\title{
pH and Temperature-sensitive Behaviors of Poly(4-vinyl pyridine-co- $N$-isopropyl acrylamide) Microgels
}

\author{
Kong Soo KIM ${ }^{1, \dagger}$ and Brian VINCENT ${ }^{2}$ \\ ${ }^{1}$ Dept. of Chemical Eng. Engineering College, Chungbuk National University, Cheongju, Chungbuk 361-763, Korea \\ ${ }^{2}$ School of Chemistry, University of Bristol, Cantock's Close, Bristol BS8 ITS, UK
}

(Received January 11, 2005; Accepted May 20, 2005; Published August 15, 2005)

\begin{abstract}
Poly(4VP-co-NIPAM) microgels were prepared from 4-vinyl pyridine (4VP) and $N$-isopropyl acrylamide (NIPAM) with methylene-bis-acrylamide (MBAm) as a cross-linking agent using partially quarternized poly(4vinyl pyridine) as emulsifier, which is a special emulsion polymerization method.

The morphology and hydrodynamic diameter of the microgel particles were characterized by TEM and photon correlation spectroscopy (PCS). The dependence of $\mathrm{pH}$ and temperature of the copolymer microgel particles were investigated and the influence of the $\mathrm{KCl}$ concentration in the microgel dispersion was observed.

Hydrodynamic diameters of the microgel particles were drastically increased below pH 5 and those of the microgel particles were depended on temperature and $\mathrm{KCl}$ concentration in the microgel dispersion. The dependence of $\mathrm{pH}$ and temperature on the microgel particles were affected by molar ratio of 4VP/NIPAM. The cross-linked copolymer microgels composed of 4VP/NIPAM ratio of $1 / 9$, exhibited broad shrinking transition. The swelling behavior for the microgel dispersion was much sensitive to the $\mathrm{KCl}$ concentration in the microgel dispersion at elevated temperature. [DOI 10.1295/polymj.37.565]

KEY WORDS Emulsion Polymerization / Poly(4VP-co-NIPAM) Microgels / pH/Temperaturesensitive Microgels / Swelling/Deswelling Behavior / Colloidal Particles /
\end{abstract}

Polymer hydrogels and microgels have a wide range of potential application in biotechnology and biomedical field. Therefore, various polymer hydrogels and microgels have been characterized where the volume change can be induced by $\mathrm{pH}$, temperature, ionic strength, and electric field of the polymer matrix. ${ }^{1-5}$

In recent years, colloidal microgel particles have attracted a lot of attention because of their rather fast kinetic response to external stimuli, which is of advantage compared to macroscopic gel particles. Thermo-sensitive hydrogels and microgels can be prepared from $\mathrm{N}$-isopropyl acrylamide that has lower critical solution temperature (LCST) at $32^{\circ} \mathrm{C}^{6-9}$ It was found that the phase transition occurs at LCST being accompanied with the coil-globule transition of single polymer chain of PNIPAM molecule in water. ${ }^{10}$ The microgels based on homopolymer poly( $N$-isopropyl acrylamide, PNIPAM) are limited in their applications due to thermally induced conformational change taking place at a fixed temperature. $\mathrm{pH}$ or temperaturesensitive copolymer microgels with other cationic charge such as poly(2-vinyl pyridine-co-styrene) and poly( $N$-isopropyl acrylamide-co-amino ethyl methacrylate) have been reported. ${ }^{11,12}$

A number of studies has been carried out on the temperature-sensitive microgel particles based on PNIPAM, which is cross-linked with methylene-bisacrylamide containing acrylic acid comonomer. ${ }^{13-15}$
Otherwise, $\mathrm{pH}$ sensitive copolymer microgels based on poly(methyl methacrylate), polystyrene, containing poly(methacrylic acid), poly(2-vinyl pyridine) have also been studied. ${ }^{16-18}$ However, $\mathrm{pH}$ and thermo-sensitive microgels based on poly(4-vinyl pyridine, P4VP) have not been synthesized and studied.

$\mathrm{pH}$ sensitive microgels could be prepared by copolymerization of monomer containing acidic and basic groups. For example, 4-vinyl pyridine is one of the monomer that process desired chemical properties such as acidity, basicity, hydrophilicity, and hydrophobicity. P4VP also can be easily cross-linked both intra and inter microgels. Therefore, the preparation method that is often used for styrene or $N$-isopropyl acrylamide based microgels cannot be applied to the case of 4-vinyl pyridine. This is probably due to the fact that the micelle nucleus cannot be formed as the polymerization progressed. Fukutomi and coworkers ${ }^{19}$ have been used the partially quarternized $\mathrm{P} 4 \mathrm{VP}$ as an emulsifier for the preparation of crosslinked P4VP microgels.

In this study, we carried out the combination of both properties by synthesizing $\mathrm{pH}$ and temperaturesensitive microgels. Synthesis and colloidal properties of poly(4VP-co-NIPAM) microgels were investigated. Especially, the hydrodynamic particle size, and the influence of $\mathrm{KCl}$ concentration as function of $\mathrm{pH}$ and temperature were also carried out. 
Table I. Preparation of the Poly(4VP-co-NIPAM) Microgels

\begin{tabular}{|c|c|c|c|c|c|c|c|}
\hline \multirow{2}{*}{$\begin{array}{l}\text { Sample } \\
\text { code }\end{array}$} & \multicolumn{2}{|c|}{ 4VP/NIPAM } & \multirow{2}{*}{$\begin{array}{c}\text { MBAm } \\
(\mathrm{wt} \%)\end{array}$} & \multirow{2}{*}{$\begin{array}{c}\text { P4VP } \\
\text { emulsifier } \\
\text { (unit mol \%) }\end{array}$} & \multicolumn{2}{|c|}{ Particle size (nm) } & \multirow{2}{*}{$\begin{array}{c}\text { Swelling } \\
\text { degree }^{\mathrm{c}} \\
(\%)\end{array}$} \\
\hline & (mole ratio) & (wt ratio) & & & $\mathrm{R}_{\mathrm{h}}^{\mathrm{a}}$ & $\mathrm{D}_{\mathrm{h}}{ }^{\mathrm{b}}$ & \\
\hline VN-1 & $9 / 1$ & $4.47 / 0.53$ & \multirow{5}{*}{7.2} & \multirow{5}{*}{5.0} & 194 & 492.6 & 154 \\
\hline $\mathrm{VN}-2$ & $7 / 3$ & $3.42 / 1.58$ & & & - & 430.0 & - \\
\hline VN-3 & $5 / 5$ & $2.40 / 2.60$ & & & 171 & 635.9 & 265 \\
\hline VN-4 & $3 / 7$ & $1.42 / 3.58$ & & & - & 514.2 & - \\
\hline VN-5 & $1 / 9$ & $0.47 / 4.53$ & & & 157 & 341.5 & 118 \\
\hline VN-6 & $1 / 9$ & $0.47 / 4.53$ & 5.0 & \multirow{2}{*}{5.0} & 207 & 498.4 & 141 \\
\hline VN-7 & $1 / 9$ & $0.47 / 4.53$ & 2.5 & & 214 & 527.0 & 146 \\
\hline
\end{tabular}

${ }^{\mathrm{a}}$ Measured on transmission electron microscopy ${ }^{\mathrm{b}}$ Measured by photon correlation spectroscopy at $\mathrm{pH} 7$ and $20^{\circ} \mathrm{C}^{\mathrm{c}}$ Calculated from equation $\left(\mathrm{D}_{\mathrm{h}}-\mathrm{R}_{\mathrm{h}}\right) / \mathrm{R}_{\mathrm{h}} \times 100$.

\section{EXPERIMENTAL}

\section{Materials}

4-vinyl pyridine (4VP, Aldrich 99\%) and chloromethyl styrene (CMS, Aldrich 99\%) were distilled under reduced pressure, and stored at $-20^{\circ} \mathrm{C}$. $\mathrm{N}$-isopropyl acrylamide (NIPAM, Kohjin) was recrystallized from 60:40 (v/v) mixture of hexane and toluene. Methylene-bis-acrylamide (MBAm, Aldrich) as a cross-linking agent was recrystallized from ethanol. 1,4-Diiodomethane was used as received.

2,2'-Azobis(2-methylpropane nitrile) (AIBN, Wako 99\%) and 2,2'-azobis(2-amidino propane) dihydrochloride (V-50, Wako 99\%) were used as initiators. Partially quarternized P4VP was used as an emulsifier. Buffer solutions were prepared from mixture of $\mathrm{KH}_{2} \mathrm{PO}_{4}$ (Aldrich, 99.8\%), $\mathrm{K}_{2} \mathrm{HPO}_{4}$ (Aldrich, 99.8\%) and distilled deionized Milli-Q water.

\section{Preparation of Polymer Emulsifier}

Partially guarternized P4VP emulsifier prepared using synthetic method, which was described by Fukitomi and co-workers ${ }^{11}$ elsewhere as follows: P4VP was synthesized from radical polymerization of 4VP in methanol using as an AIBN initiator. After $10 \mathrm{~g}$ of P4VP was dissolved in $50 \mathrm{~mL}$ methanol, $3.5 \mathrm{~mL}$ of CMS (26.5 mol \% for 4VP units) was added while stirring for $24 \mathrm{~h}$ at room temperature. Then $3 \mathrm{~mL}$ ( $50.8 \mathrm{~mol} \%$ for $4 \mathrm{VP}$ units) of iodometane was added into the reaction mixture and stirred at room temperature for $24 \mathrm{~h}$. The solution was diluted with $200 \mathrm{~mL}$ of distilled water and stored in a refrigerator at $4{ }^{\circ} \mathrm{C}$.

\section{Synthesis of Copolymer Microgels}

Poly(4VP-co-NIPAM) microgel particles were prepared using partially quarternized $\mathrm{P} 4 \mathrm{VP}$ emulsifier by emulsion polymerization at $70^{\circ} \mathrm{C}$ for $8 \mathrm{~h}$. In this polymerization, molar ratio of $4 \mathrm{VP} / \mathrm{NIPAM}$ was varied to $10 / 0,9 / 1,7 / 3,5 / 5,3 / 7$ and $1 / 9$ with $7.2 \mathrm{wt} \%$
MBAm, and also the copolymer microgels composed of $4 \mathrm{VP} / \mathrm{NIPAM}$ ratio of $1 / 9$ with 2.5 and $5.0 \mathrm{wt} \%$ MBAm were prepared, respectively. The detail feed compositions in polymerization are listed in Table I. Emulsion polymerization was carried out in a 500 $\mathrm{mL}$ three-necked, round bottomed flask equipped with a nitrogen inlet, condenser and teflon paddle stirrer.

Different molar ratio of 4VP/NIPAM and given amount of MBAm were dispersed into $200 \mathrm{~mL}$ distilled water. 5 min later, 5 unit mol \% P4VP emulsifier to 4VP monomer (emulsifier/4VP unit) and V-50 as an initiator were added. The reaction mixture was deoxygenated by stirring at $300 \mathrm{rpm}$ under a nitrogen flow for $30 \mathrm{~min}$, and then the reaction mixture was stirred at $70^{\circ} \mathrm{C}$ for $6 \mathrm{~h}$. All microgel particles were cleaned by repetitive centrifugation and redispersion in Milli-Q water several times.

\section{Characterization}

The morphology of the copolymer microgels were observed using transmission electron microscope (TEM, Joel JEM-100CX). Small amount of the copolymer microgel dispersion was infinitely diluted with distilled water. The diluted samples were supported on carbon-coated copper grids.

Hydrodynamic diameters of the microgel particles were determined by photo correlation spectroscopy (PCS) using a Zeta Plus dynamic light scattering apparatus (Brookhaven Instruments) fitted with a $635 \mathrm{~nm} \mathrm{He}-\mathrm{Ne}$ laser and detector at $90^{\circ}$. Samples for these experiments were prepared in the buffer solution made by mixing appropriate volumes of $1 \times 10^{-3} \mathrm{M} \mathrm{KH}_{2} \mathrm{PO}_{4}$ and $1 \times 10^{3} \mathrm{M} \mathrm{K}_{2} \mathrm{HPO}_{4}$, and followed by 100 -fold volumetric dilution, giving a final microgel concentration of $5 \times 10^{3} \mathrm{wt} \%$.

Transmittance measurements for the microgel dispersions at a wavelength of $500 \mathrm{~nm}$ were performed as a function of temperature in the different $\mathrm{KCl}$ concentration using UV/Vis. spectrophotometer (PerkinElmer Lambda 5). 


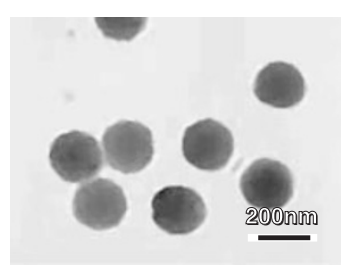

(a)

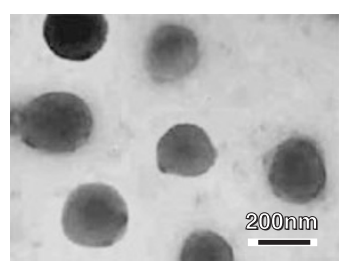

(d)

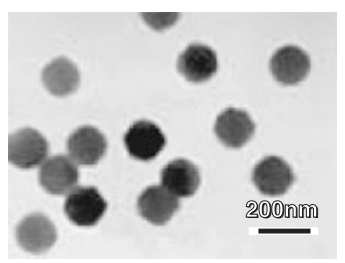

(b)

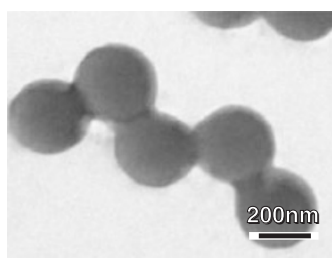

(e)

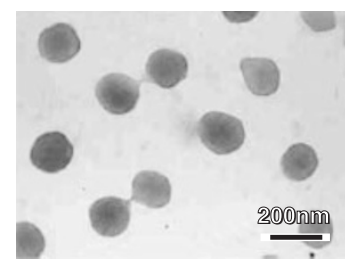

(c)

Figure 1. Transmission electron micrographs of the poly(4VP-co-NIPAM) microgels; Molar ratio of 4VP/NIPAM: (a) 9/1 (7.2 wt \% MBAm) (b) $5 / 5$ (7.2 wt \% MBAm) (c) $1 / 9$ (7.2 wt \% MBAm) (d) $1 / 9$ (5.0 wt \% MBAm) (e) $1 / 9$ (2.5 wt \% MBAm).

\section{RESULTS AND DISCUSSION}

Poly(4VP-co-NIPAM) microgels were prepared from the different molar ratio of $4 \mathrm{VP} / \mathrm{NIPAM}$ and different wt $\%$ of MBAm as cross-linking agent by a special emulsion polymerization using partially guarternized P4VP emulsifier.

Particle size of the microgels was distributed in the range of 157-214 nm from TEM measurement. TEM micrographs of the microgel particles are shown in Figure 1. The particle size of microgels was increased with increasing molar ratio of $4 \mathrm{VP} / \mathrm{NIPAM}$ and the change in particle morphology was irregular spheres with different molar ratio of 4VP/NIPAM. This could be caused by the phase separation of incompatible domains with the microgel particles. The particle size of the microgels composed of $4 \mathrm{VP} / \mathrm{NIPAM}$ ratio of $1 / 9$ was decreased as expected for more highly cross-linked microgel particles.

The hydrodynamic diameters for the microgel particles as function of $\mathrm{pH}$ at $20^{\circ} \mathrm{C}$ are shown in Figures $2 \mathrm{a}$ and $2 \mathrm{~b}$. In these measurement $1 \times 10^{-3} \mathrm{M}$ phosphate buffer was used and hydrodynamic diameter of the microgel particles was represented the mean of measuring value of each samples. The hydrodynamic diameter of the microgel particles was drastically increased below pH 5 and was nearly not changed in the range of $\mathrm{pH}$ 5-7. Under alkaline conditions, however, the microgel particles were flocculated.

The $\mathrm{pKa}_{1}$ and $\mathrm{pKa}_{2}$ of P4VP is around 3 and 5 , respectively. Under acidic conditions the pyridine groups get protonated and the increased charge density on the microgel particles should enhance degree of swelling. It was indicated that $\mathrm{pH}$ dependent on swelling behavior for the microgel particles was increased with introduction of cationic charged P4VP into the network.

The hydrodynamic diameters as a function of $\mathrm{pH}$ for the microgel particles composed of 4VP/NIPAM ratio of $1 / 9$ with different cross-linking degree at $20^{\circ} \mathrm{C}$ are shown in Figure 2c. The hydrodynamic diameter for the microgel particles were decreased with increasing the cross-linking degree and the $\mathrm{pH}$ dependence of the microgel particles with $7.2 \mathrm{wt} \%$ of MBSA was relatively lower.

The swelling behavior of the microgel particles composed of different molar ratio of $4 \mathrm{VP} / \mathrm{NIPAM}$ with $7.2 \mathrm{wt} \% \mathrm{MBAm}$ as function of temperature at pH 3 and pH 6 is shown in Figures 3a and 3b. Hydrodynamic diameter of the microgel particles composed of $4 \mathrm{VP} /$ NIPAM ratio of $3 / 7,1 / 9$ was slightly decreased up to 30 and $35^{\circ} \mathrm{C}$, respectively. However, that of the microgel particles was sharply increased up to $50^{\circ} \mathrm{C}$, indicating that aggregation of the colloidal particles occurred at elevated temperature. Whereas, hydrodynamic diameter of the microgel particles composed of $4 \mathrm{VP} /$ NIPAM ratio of $5 / 5$ was continuously increased with increasing temperature.

At $\mathrm{pH} \mathrm{3}$, the shrinking transition and LCSTs by PNIPAM of the microgel particles composed of $4 \mathrm{VP} / \mathrm{NIPAM}$ were not represented. The increase in the molar ratio of $4 \mathrm{VP} / \mathrm{NIPAM}$ allows protonation of pyridine groups, which seems to prefer swelling at lower $\mathrm{pH}$ range. At $\mathrm{pH} 6$ hydrodynamic diameter of the microgel particles composed of $4 \mathrm{VP} / \mathrm{NIPAM}$ ratio of $1 / 9$ was decreased with increasing temperature and that of the microgel particles composed of $4 \mathrm{VP} / \mathrm{NIPAM}$ ratio of $3 / 7$ was not nearly changed up to $35^{\circ} \mathrm{C}$ but continuously increased above $35^{\circ} \mathrm{C}$. On the other hand, the microgel particles composed of $4 \mathrm{VP} / \mathrm{NIPAM}$ ratio of $5 / 5$ was continuously 
(a)

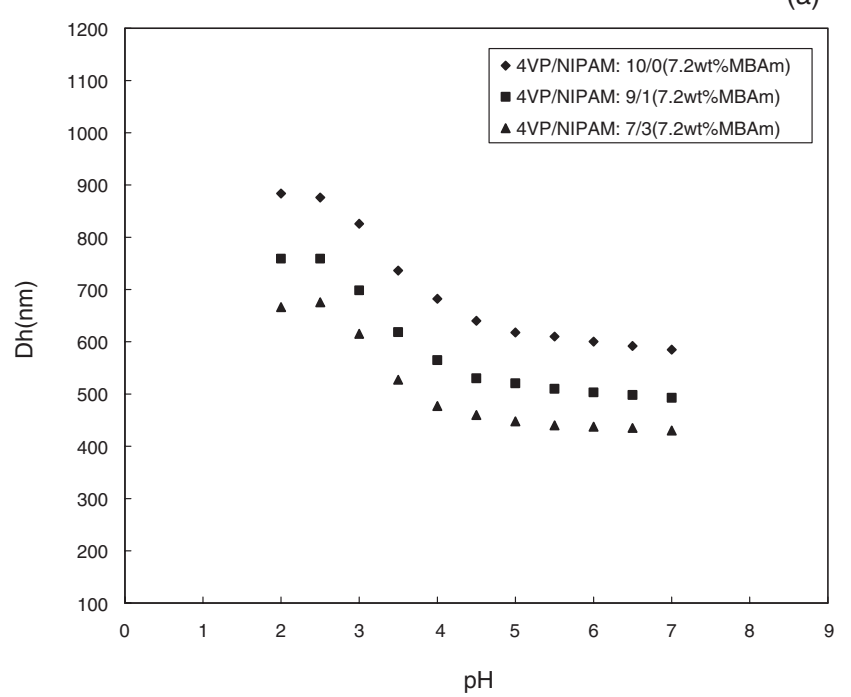

(b)

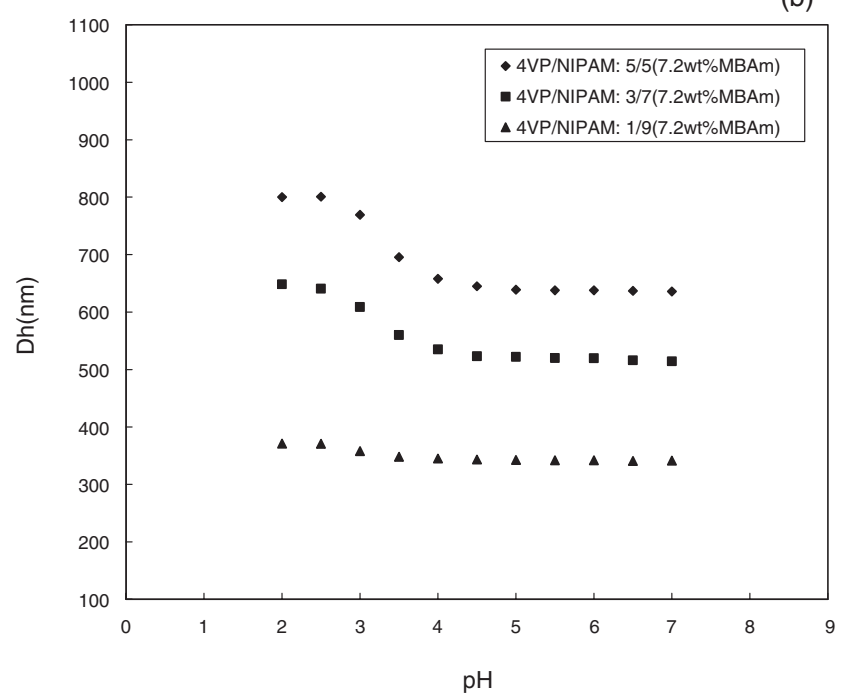

(c)

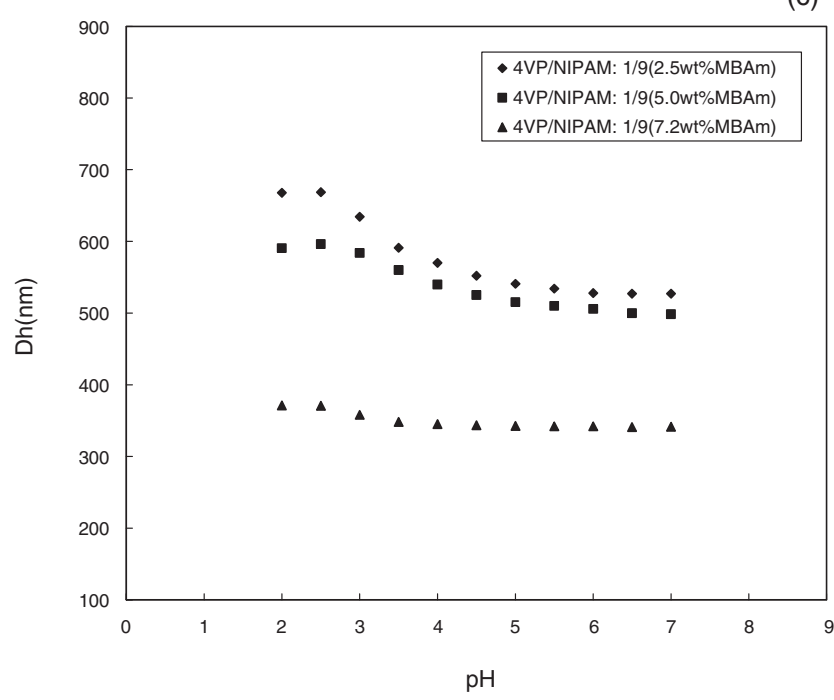

Figure 2. Hydrodynamic diameter for the poly(4VP-coNIPAM) microgels as a function of $\mathrm{pH}$ at $20^{\circ} \mathrm{C}$. (a)

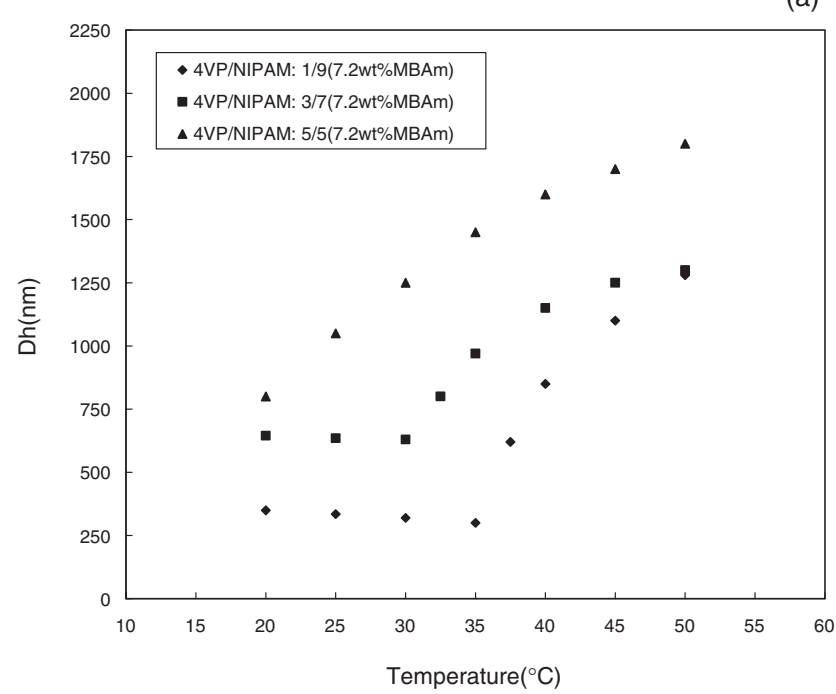

(b)

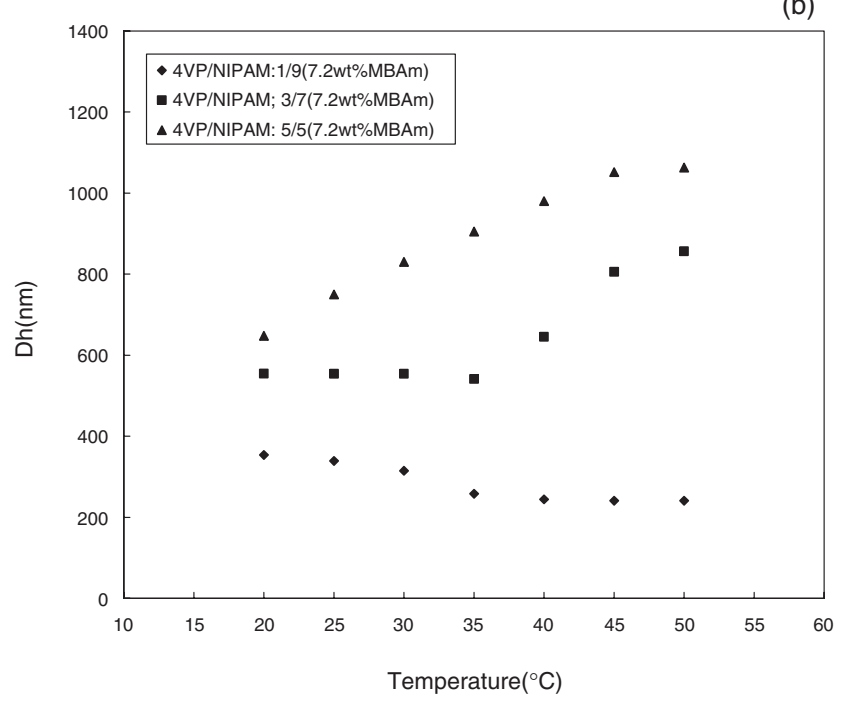

Figure 3. Hydrodynamic diameter for the poly(4VP-coNIPAM) microgels as a function of temperature at $\mathrm{pH} 3$ (a) and pH 6 (b).

increased with increasing temperature. Under acidic conditions, the size of an aggregates with temperature depends on the content of P4VP present in the microgels. A reasonable explanation for this effect is to break the inter-particle hydrogen bonding between nitrogen on pyridine rings of the P4VP side chain and the amide groups of PNIPAM and to aggregate between swollen microgel particles.

The hydrodynamic diameters as a function of temperature for the microgel particles composed of $4 \mathrm{VP} /$ NIPAM ratio of $1 / 9$ with different cross-linking degree at $\mathrm{pH} 6$ are shown in Figure 4. The shrinking transition of the microgel particles observed at slightly higher temperature range as to cross-linked PNIPAM. Hydrodynamic diameter of the microgel particles cross-linked with $2.5 \mathrm{wt} \%$ MBAm was sharply increased around the critical temperature indicating 


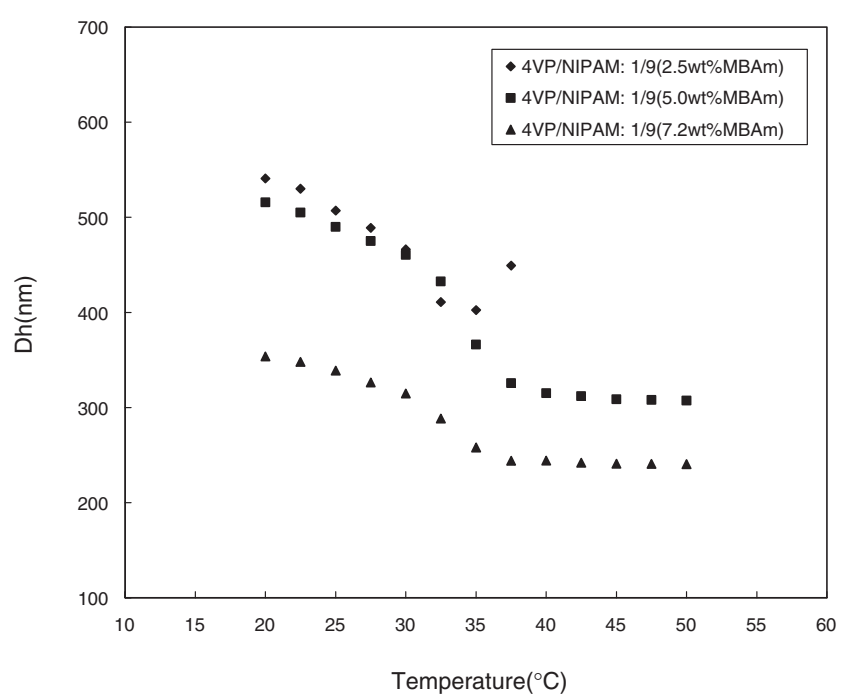

Figure 4. Hydrodynamic diameter as a function of temperature for the copolymer microgels at $\mathrm{pH} 6$.

aggregation of the microgel particles above $35^{\circ} \mathrm{C}$. While hydrodynamic diameters of the microgel particles cross-linked with 5.0 and 7.2 wt \% MBAm were gradually decreased in the temperature range of 20 $40{ }^{\circ} \mathrm{C}$. The hydrodynamic diameter of the microgel particles cross-linked with $7.2 \mathrm{wt} \%$ MBAm is smaller than that cross-linked with 2.5 and $5.0 \mathrm{wt} \% \mathrm{MBAm}$. However, the hydrodynamic diameter of the microgel particles was not nearly changed above $37.5^{\circ} \mathrm{C}$. It is shown that the continuous variation of hydrodynamic diameter is not due to coagulation, since the microgel particles do not flocculate at any temperature range of $20-50{ }^{\circ} \mathrm{C}$.

The temperature dependence on swelling behavior of the microgel particles composed of 4VP/NIPAM ratio of $1 / 9$ with $7.2 \mathrm{wt} \% \mathrm{MBAm}$ at $\mathrm{pH} 3$ and $\mathrm{pH} 9$ in Figure 5. The hydrodynamic diameters of the microgel particles as function of temperature at $\mathrm{pH} 3$ were markedly larger than that at $\mathrm{pH} 9$. It becomes clear evidence that the size of the microgel particles as well as the shrinking process depend critically on $\mathrm{pH}$. This is in accord with the fact that P4VP is fully dissociated at lower $\mathrm{pH}$.

The transmittance changes for $0.02 \mathrm{wt} \%$ microgel dispersion in the different $\mathrm{KCl}$ concentration are shown in Figure 6. The transmittance changes in $0.5 \mathrm{M} \mathrm{KCl}$ solution for the microgel dispersions composed of $4 \mathrm{VP} / \mathrm{NIPAM}$ ratio of $1 / 9$ with $7.2 \mathrm{wt} \%$ MBAm were decreased with increasing temperature and a broad shrinking transition takes place around the temperature range of $30-40^{\circ} \mathrm{C}$. However, the microgel dispersions composed of 4VP/NIPAM ratio of $5 / 5,9 / 1$ were slightly increased with increasing temperature and disappeared the shrinking transition.

In general, an increase in ionic strength diminishes

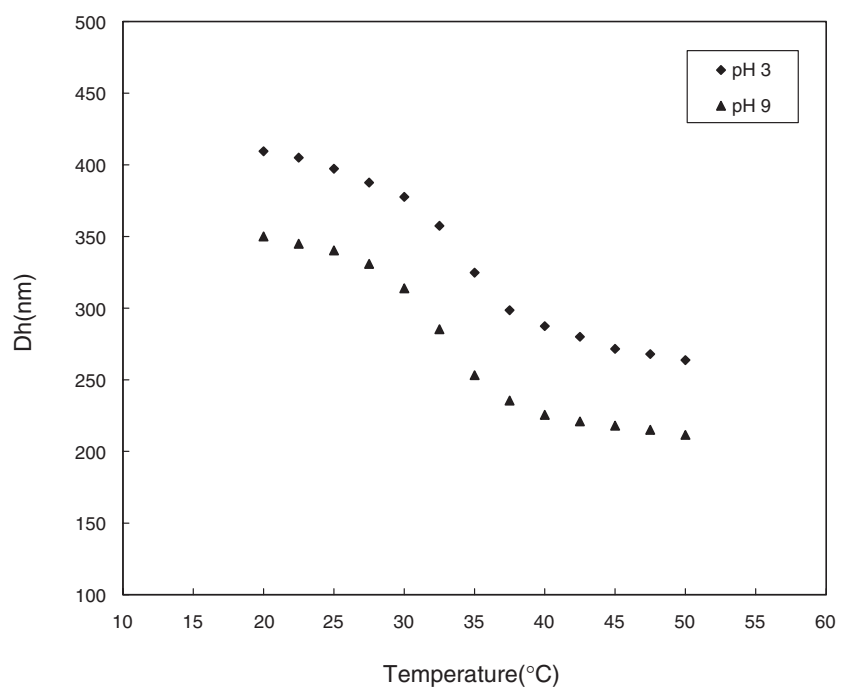

Figure 5. Hydrodynamic diameter as a function of temperature for the poly(4VP-co-NIPAM) microgel at $\mathrm{pH} 3$ and 9; Molar ratio of $4 \mathrm{VP} / \mathrm{NIPAM}$ : $1 / 9$ (7.2 wt \% MBAm).

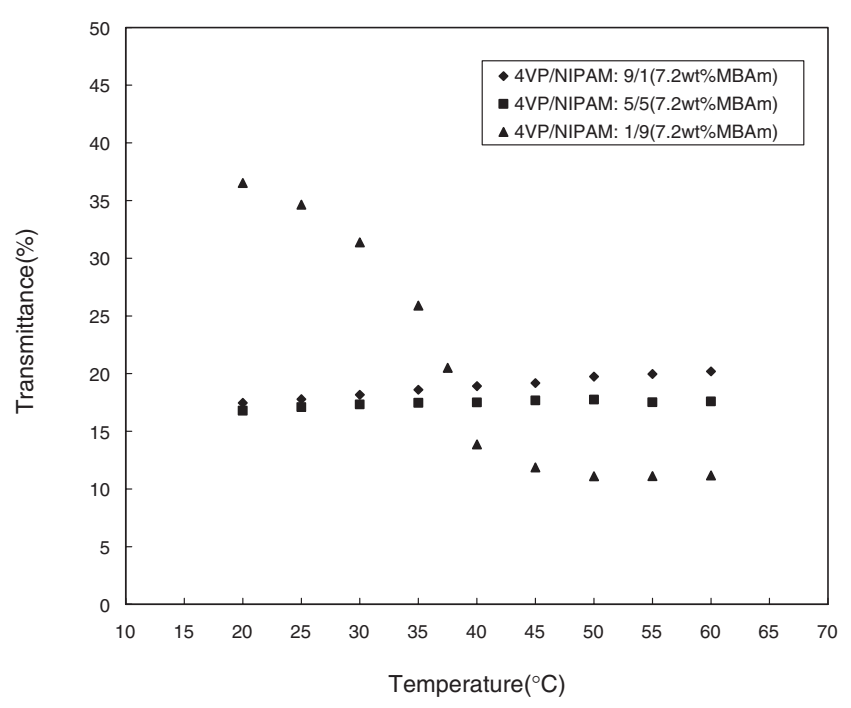

Figure 6. Transmittance at $550 \mathrm{~nm}$ for the poly(4VP-coNIPAM) microgels as a function of temperature in $0.5 \mathrm{M} \mathrm{KCl}$ solution at $\mathrm{pH}$ 6; Conc. of microgel: $0.02 \mathrm{wt} \%$.

the repulsive electrostatic forces between the protonated pyridine residues on the particle surface. Moreover, changes of the osmotic pressure and the shielding effect caused by the counter ions under higher ionic strength. ${ }^{13}$ Therefore, it is expected that addition of $\mathrm{KCl}$ solution would have a strong effect on the swelling behavior of the microgels.

The transmittance changes for the microgel dispersions in the different $\mathrm{KCl}$ concentration are shown in Figure 7 . The transmittance changes for the microgel dispersion composed of $4 \mathrm{VP} / \mathrm{NIPAM}$ ratio of $1 / 9$ with $5.0 \mathrm{wt} \% \mathrm{MBAm}$ in 0.05 and $0.1 \mathrm{M} \mathrm{KCl}$ solution decreased in the temperature range of $30-35^{\circ} \mathrm{C}, 30$ $40^{\circ} \mathrm{C}$, respectively. The transmittance for the micro- 


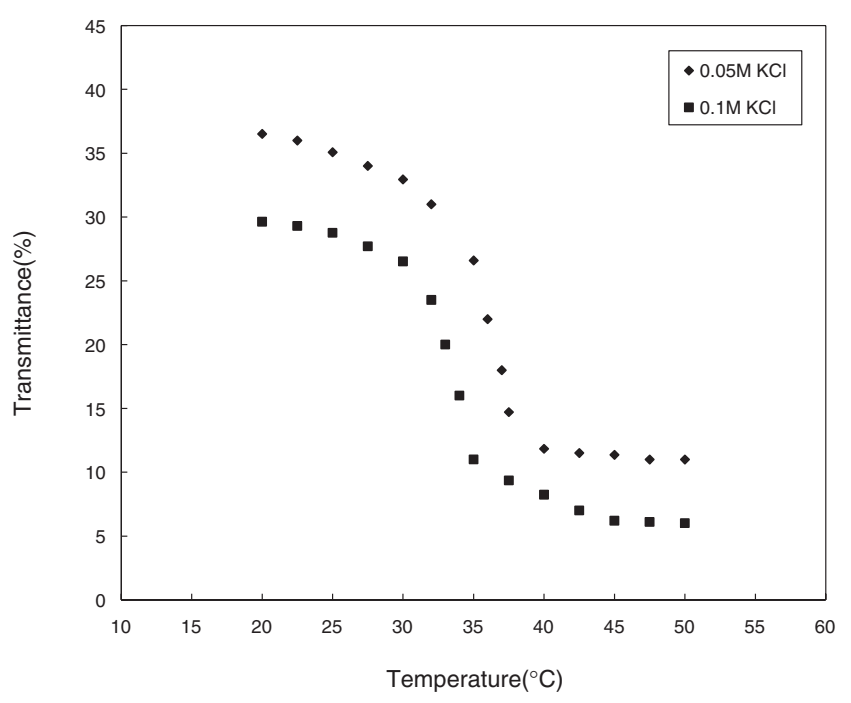

Figure 7. Transmittance at $550 \mathrm{~nm}$ for the poly(4VP-coNIPAM) microgel as a function of temperature in different concentration of $\mathrm{KCl}$ solution at $\mathrm{pH}$ 6; Molar ratio of 4VP/NIPAM: $1 / 9$ (5.0 wt \% MBAm); Conc. of microgel: $0.02 \mathrm{wt} \%$.

gel dispersion in $0.1 \mathrm{M} \mathrm{KCl}$ solution was lower than that in $0.05 \mathrm{M} \mathrm{KCl}$ solution. It indicates that the transmittance decrease is due to the shrinking of microgel particles. Therefore, the volume transition by the shrinking of microgel particles also shifted to lower temperature. This effect can be attributed to reduce osmotic swelling pressure, because a high $\mathrm{KCl}$ concentration in the microgel dispersion has a consequence that the concentration gradient between the $\mathrm{KCl}$ concentration in the microgel dispersion inside and outside of the microgel particles.

\section{CONCLUSIONS}

Poly(4VP-co-NIPAM) microgels were prepared from 4VP and NIPAM with MBAm as cross-linking agent by a special emulsion polymerization method using partially quarternized P4VP as an emulsifier.

The morphology of the microgel particles exhibited the spherical particles with hydrophilic PNIPAM hydrogel layer and the particle size of the microgels was in the range of $157-214 \mathrm{~nm}$.

The microgel particles were exhibited $\mathrm{pH}$ and temperature response behaviors. Their swelling behaviors as a function of $\mathrm{pH}$ and temperature were depended on molar ratio of $4 \mathrm{VP} / \mathrm{NIPAM}$ and wt $\%$ of MBAm for total monomers. $\mathrm{pH}$ dependence on swelling behavior of the microgel particles was significantly affected with introduction of cationic charged 4VP, but shrinking transition by the PNIPAM was disappeared and aggregated with increasing temperature. Particularly, the cross-linked microgel particles composed of 4VP/NIPAM ratio of $1 / 9$ exhibited broad shrinking transition around $30-37.5^{\circ} \mathrm{C}$.

The $\mathrm{KCl}$ concentration in the microgel dispersion was shown a drastic influence on shrinking of the cross-linked microgel particles composed of $4 \mathrm{VP} /$ NIPAM ratio of $1 / 9$. The swelling behavior for the microgel particles was decreased with increasing $\mathrm{KCl}$ concentration as temperature increase.

\section{REFERENCES}

1. R. A. Siegel and B. A. Firestone, Macromolecules, 21, 3254 (1988).

2. T. Tanaka, I. Nishio, S. T. Sun, and S. Ueno-Nishio, Science, 218, 467 (1982).

3. G. Chen and A. S. Hoffman, Nature, 313, 49 (1995).

4. M. Shibayama, F. Ikkai, S. Ionamoto, S. Nomura, and C. C. Han, J. Chem. Phys., 105, 4358 (1996).

5. J. Zang and N. A. Peppas, Macromolecules, 33, 102 (2000).

6. R. H. Pelton, H. M. Pelton, A. Morphesis, and R. L. Rowell, Langmuir, 5, 816 (1989).

7. K. Makino, S. Yamamoto, K. Fujimoto, H. Kawaguchi, and H. Ohsima, Colloid Interface Sci., 168, 251 (1994).

8. H. G. Schild and D. A. Tirrell, J. Phys. Chem., 94, 4352 (1990).

9. Y. Hirokawa, T. Tanaka, and E. S. Matsuo, J. Chem. Phys., 81, 6379 (1984).

10. K. Kubota, S. Fujishige, and I. Ando, J. Phys. Chem., 94, 5154 (1990).

11. A. Loxley and B. Vincent, Colloid Polym. Sci., 275, 1108 (1997).

12. D. Duracher, F. Sauzedte, A. Elaissari, A. Perrin, and C. Pichot, Colloid Polym. Sci., 276, 219 (1998).

13. K. Kratz, T. Hellweg, and W. Eimer, Colloid Surf., A: Physicochem. Eng. Aspects, 170, 137 (2000).

14. F. Ikkai, M. Shibayama, and C. C. Han, Macromolecules, 31, 3275 (1998).

15. B. E. Rodriquez, M. S. Wolfee, and M. Fryd, Macromolecules, 27, 6642 (1994).

16. K. Makino, H. Agata, and H. Ohshima, J. Colloid Interface Sci., 230, 128 (2000).

17. T. Sawai, S. Yamazaki, Y. Ikariyama, and M. Aizawa, Macromolecules, 24, 2117 (1991).

18. S. Katayama, Y. Hirokawa, and T. Tanaka, Macromolecules, 17, 2641 (1984).

19. G. H. Ma and T. Fukutomi, J. Appl. Polym. Sci., 43, 1451 (1991). 